\title{
Dietary Betaine Reduces the Negative Effects of Cyclic Heat Exposure on Growth Performance, Blood Gas Status and Meat Quality in Broiler Chickens
}

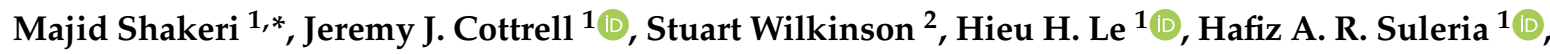 \\ Robyn D. Warner ${ }^{1}$ (D) and Frank R. Dunshea ${ }^{1, *(D)}$ \\ 1 Faculty of Veterinary and Agricultural Sciences, The University of Melbourne, Parkville, VIC 3010, Australia; \\ jcottrell@unimelb.edu.au (J.J.C.); huul1@student.unimelb.edu.au (H.H.L.); \\ hafiz.suleria@unimelb.edu.au (H.A.R.S.); robyn.warner@unimelb.edu.au (R.D.W.) \\ 2 Feedworks Pty Ltd., Romsey, VIC 3434, Australia; stuart.wilkinson@feedworks.com.au \\ * Correspondence: mshakeri@student.unimelb.edu.au (M.S.); fdunshea@unimelb.edu.au (F.R.D.)
}

Received: 22 April 2020; Accepted: 14 May 2020; Published: 16 May 2020

\begin{abstract}
Heat stress (HS) impairs growth performance and has a severe impact on lipid and protein metabolism, leading to serious adverse effects on meat quality. Forty-eight day-old-male Ross-308 chicks were assigned to two temperature conditions, thermoneutral or cyclical HS, and fed with either a control diet $(\mathrm{CON})$ or the $\mathrm{CON}$ plus betaine (BET). Heat stress increased rectal temperature $(p<0.001)$, respiration rate $(p<0.001)$ and increased blood $\mathrm{pH}(p=0.017)$, indicating that HS caused respiratory alkalosis. Heat stress reduced body weight during the final stage of growing period $(p=0.005)$, while BET improved it $(p=0.023)$. Heat stress tended to reduce breast muscle water content and drip loss $(p=0.089$ and $p=0.082)$, while both were improved with BET ( $p=0.008$ and $p=0.001)$. Heat stress tended to reduce the myofibril fragmentation index $(p=0.081)$ whereas it increased with BET $(p=0.017)$. Heat stress increased thiobarbituric acid reactive substances $(p=0.017)$, while BET improved it $(p=0.008)$. Meat tenderness was not affected by HS, but was improved with BET $(p<0.001)$. In conclusion, BET improved growth performance over the latter stages of the growing period, and improved product quality of broiler chickens when chickens exposed to HS.
\end{abstract}

Keywords: cyclic heat stress; betaine; growth performance; meat quality; arterial blood gas; hormone activity; broiler chickens

\section{Introduction}

With the severity and incidence of cyclic heat events grow along with a rise in poultry production in sub-tropical and tropical areas [1], it is necessary to improve the management regarding heat stress (HS). Broiler chickens reared under HS exhibit a decreased growth performance and increased respiration rate and body temperature. There is also some limited evidence that skeletal muscle from broilers exposed to HS has reduced protein synthesis and proteolysis [2] which may impact on subsequent meat quality. Other possible impacts on chicken meat quality include reduced $\mathrm{pH}$, resulting in paler meat [3], increased level of lipid oxidation [4] and altered muscle fiber structure [5,6]. As a result, there is a high demand for affordable nutritional strategies to ameliorate the adverse effects of HS on meat quality and growth performance in domestic animals $[7,8]$. In this regard, dietary betaine (BET) is considered as an additive which has been shown to improve growth performance in HS chickens and possibly meat quality.

Betaine (trimethylglycine) is a ubiquitous amino acid derivative which can be extracted from sugar beets. Betaine protects tissues against osmotic stress thereby increasing cellular water retention [9], 
acts as a methyl donor which improves synthesis of methionine and carnitine [10]. Betaine has antioxidant function that can reduce oxidative stress in broiler chickens under HS [11,12]. Furthermore, it reduces maintenance requirements and heat production by reducing the activity of the ion pumps involved in cellular osmoregulation, allowing more energy for growth [13]. Therefore, that purpose of the present experiment was to investigate whether dietary BET could ameliorate the negative effects of HS on growth performance, physiological responses and meat quality in contemporary broiler chickens.

\section{Materials and Methods}

\subsection{Ethics Statement}

The experiment was approved by the Animal Ethics Committee, The University of Melbourne, Australia (Protocol no. 181442601.1).

\subsection{Animals, Experimental Design and Diets}

Forty-eight day-old male Ross-308 chicks were purchased from a local hatchery (Tri Foods Pty Ltd., Bannockburn Victoria, Australia) within $2 \mathrm{~h}$ distance from the research facility. Upon arrival the chicks were wing-tagged, individually weighed and randomly assigned to 16 pens of 3 chicks, and allocated to two climate controlled rooms ( 8 pens/room). There were an additional 16 pens of chicks from the same hatching in each room that were utilized in a concurrent experiment to be reported separately. The temperature in both rooms was $33^{\circ} \mathrm{C}$ for the first 7 days and dropped to $25^{\circ} \mathrm{C}$ from days 7 to 21 for the TN group $\left(1{ }^{\circ} \mathrm{C} / 2\right.$ days), before being maintained at $25^{\circ} \mathrm{C}$ from days 21 to 35 ; or cyclic HS, the temperature was at $33^{\circ} \mathrm{C}$ from days 7 to 35 for $8 \mathrm{~h}$ from 9 am to $5 \mathrm{pm}$ and dropped to TN temperature for $16 \mathrm{~h}$ from $5 \mathrm{pm}$ to $9 \mathrm{am}$. The environmental humidity was approximately $40-55 \%$ throughout the experiment. Lights were on for both rooms continuously for the first 3 days was decreased $(1 \mathrm{~h} /$ day $)$ to $20 \mathrm{~h}$. The pen dimensions were $1 \mathrm{~m} \times 0.5 \mathrm{~m}$ and the floor each pen was covered with a depth of $\sim 10 \mathrm{~cm}$ with wood shavings. Feed was either a control diet (CON) or the CON diet plus $1 \mathrm{~g} / \mathrm{kg}$ betaine (Betafin, DuPont, UK) (BET). Feed (Feedworks Bestmix, Sydney, Australia) was provided as a starter from days 1 to 14 (CP $24.9 \%$ and $12.0 \mathrm{MJ} \mathrm{ME} / \mathrm{kg}$ ), grower from days 15 to 28 (CP $23.1 \%$ and 12.4 MJ ME $/ \mathrm{kg}$ ) and finisher from days 29 to 35 (CP 21.3\% and $12.7 \mathrm{MJ} \mathrm{ME} / \mathrm{kg}$ ). Feed and water were available at all times. Body weight gain and feed intake were recorded weekly to determine average daily body weight gain (ADG), average daily feed intake (ADFI) and feed conversion ratio (FCR).

Commencing on day 14, rectal temperature was measured weekly at 08:00, 12:00 and 15:00 with a thermometer (Comark PDT 300, Norwich, UK). The thermometer was inserted into the rectum for $30 \mathrm{~s}$. Respiration rate was measured ( 2 chickens/pen) at $12 \mathrm{pm}$ on day 34 with a smartphone (iPhone 7 , Apple Inc., Cupertino, CA, USA) to measure number of breaths per minutes (bpm).

Approximately $3 \mathrm{~mL}$ Blood sample (16 chickens, 1/pen) was collected from the wing vein (4 from each treatment) at the end of experiment. Furthermore, some of the blood sample ( 0.3 mL) was added into an blood gas analyzer (EPOC ${ }^{\circledR}$; Alere, Waltham, MA, USA) to measure blood chemistry parameters. The rest of blood sample was centrifuged at $15,000 \times g$ for $15 \mathrm{~min}$ to obtain plasma for subsequent betaine and thyroid hormone determination.

\subsection{Slaughter and Objective Meat Quality Measures}

At the end of the experiment, chickens were stunned (Mitchell Engineering Food Equipment, Pty Ltd., Clontarf, QLD, Australia) and then exsanguinated after which they were submerged in a water bath $\left(60 \pm 1{ }^{\circ} \mathrm{C}\right.$ for $\left.80 \mathrm{~s}\right)$ in preparation for mechanical feather removal (Bellsouth Poultry Equipment, Pty Ltd., Australia). After feather removal, the left breast muscles (m. Pectoralis major and minor) were partially skinned and $\mathrm{pH}$ measured approximately within $10 \mathrm{~min}$ post-slaughter with a calibrated polypropylene electrode (Ionode IJ44A, Pty Ltd., Queensland, Australia) and portable pH meter (WP-80M, Pty Ltd., Queensland, Australia). Chicken carcasses were then rapidly chilled by 
placing in sealed plastic bags, suspension in cold water $\left(\sim 4{ }^{\circ} \mathrm{C}\right.$ for $\left.40 \mathrm{~min}\right)$ before transfer to a cool room $\left(4{ }^{\circ} \mathrm{C}\right)$ to simulate commercial conditions. At $24 \mathrm{~h}$ after slaughter, the whole breast muscles (both sides) were removed for subsequent objective meat quality and betaine determination. In addition to the initial muscle $\mathrm{pH}$ measurement, $\mathrm{pH}$ was also determined at $1 \mathrm{~h}$ and $24 \mathrm{~h}$ after slaughter.

To measure muscle drip loss, samples $(10 \mathrm{~g})$ were weighed (freshly trimmed and covering fat or connective tissue were removed) and then suspended in a bottle with a sealed cap for $48 \mathrm{~h}$. To measure cooking loss, $80 \mathrm{~g}$ of muscle samples (were cooked in a zip plastic bag in an $80 \pm 1{ }^{\circ} \mathrm{C}$ water bath for $40 \mathrm{~min}$. After cooking, samples were cooled with cool water for $10 \mathrm{~min}$, then dried gently with paper towel before reweighing to remove extra moisture produced on the surface. Warner-Bratzler shear force (WBSF) was determined on the cooked samples after overnight chilling $\left(4^{\circ} \mathrm{C}\right)$ as previously described [14]. A Minolta chromameter CR-400 with $8 \mathrm{~mm}$ aperture (Minolta Pty Ltd., Tokyo, Japan, light source D65, observer angle $2^{\circ}$ ) was used to determine meat colour at $24 \mathrm{~h}$ and $72 \mathrm{~h}$ post-slaughter as previously described [14]. Breast muscle was stored at $4{ }^{\circ} \mathrm{C}$ on retail trays, over-wrapped before measuring colour in triplicate at $24 \mathrm{~h}$ and $72 \mathrm{~h}$.

\subsection{Biochemical and Endocrinologal Analyses}

Muscle myofibrillar fragmentation index (MFI) and thiobarbituric acid reactive substances (TBARS) were determined as described in detail previously [14]. Plasma and muscle betaine concentrations were determined using High-Performance Liquid Chromatography (Waters 2998, Massachusetts, USA) technique as described by [14]. Thyroid hormones, triiodothyronine $\left(T_{3}\right)$ and thyroxine $\left(T_{4}\right)$, were measured using free radioimmunoassay kits in plasma (MP Biomedicals, LLC Diagnostics Division, Solon, Ohio, USA) and explained previously [14].

Muscle protein carbonyl concentrations were determined using a previously published method with some modifications [15]. Muscle $(1 \pm 0.01 \mathrm{~g})$ was minced and homogenized (IKA Ultra Turrax ${ }^{\circledR} \mathrm{T}$ 25 digital, Selangor, Malaysia) in $5 \mathrm{~mL}$ pyrophosphate buffer $(2 \mathrm{mM}$ sodium pyrophosphate, $10 \mathrm{mM}$ tris maleate, $100 \mathrm{mM}$ potassium chloride and $2 \mathrm{mM}$ ethylene tetra acetic acid at $\mathrm{pH}=7.4)$ at $10,000 \times \mathrm{g}$ for $30 \mathrm{~s}$. After splitting into 2 tubes, $9 \mathrm{~mL}$ hydrogen chloride-acetone $(3: 100 v / v)$ was added in each tube, vortexed and centrifuged at $5000 \times g$ for $5 \mathrm{~min}$ at $4{ }^{\circ} \mathrm{C}$. The mixture was washed twice with $1 \mathrm{~mL}$ trichloroacetic acid $10 \%$ and centrifuged at $5000 \times g$ for $5 \mathrm{~min}$ at $4{ }^{\circ} \mathrm{C}$. Tube 1 was then incubated with $0.5 \mathrm{~mL} 10 \mathrm{mM}$ 2,4 dinitrophenylhydrazine (DNPH) dissolved in $2 \mathrm{mM}$ hydrogen chloride whereas tube 2 was incubated with only $0.5 \mathrm{~mL} 2 \mathrm{mM}$ hydrogen chloride to calculate protein concentration. Both tubes were kept in darkness for 30 min (vortexed for $10 \mathrm{~s}$ every $10 \mathrm{~min}$ ). Next, $0.5 \mathrm{~mL} 20 \%$ trichloroacetic acid was added to both tubes which were vortexed and placed on ice for $10 \mathrm{~min}$ before being centrifuged at $5000 \times \mathrm{g}$ for $5 \mathrm{~min}$ at $4{ }^{\circ} \mathrm{C}$. After washing with $1 \mathrm{~mL}$ trichloroacetic acid $20 \%$ the centrifuged pellets were washed 3 times with $1 \mathrm{~mL}$ ethanol ethyl acetate and then centrifuged at $5000 \times \mathrm{g}$ for $5 \mathrm{~min}$ at $4{ }^{\circ} \mathrm{C}$. Then, $1 \mathrm{~mL}$ of a guanidine solution (6 M guanidine hydrochloride dissolved in $20 \mathrm{mM}$ potassium dihydrogen phosphate at $\mathrm{pH}$ 2.3) was added and the mixture shaken overnight at $4{ }^{\circ} \mathrm{C}$. Absorbance was measured at $370 \mathrm{~nm}$ to determine DNPH concentration in tube 1 and at $280 \mathrm{~nm}$ to determine protein concentration in tube 2.

\subsection{Branch Chain Amino Acid}

Branch chain amino acid (BCAA) was measured based on a protocol provided by the manufacturer (Abcam, Discovery Drive Cambridge Biomedical Campus, Cambridge, UK). In brief, $10 \mu \mathrm{L}$ of plasma samples or different level of standards were mixed with assay buffer (provided by the manufacturer), in a 96 wells plate, to bring the total volume to $50 \mu \mathrm{L}$. Then, $50 \mu \mathrm{L}$ of reaction mix reagent was added to the mixture, incubated under room temperature for $30 \mathrm{~min}$ in a dark place before the plate was read at $450 \mathrm{~nm}$ using Varioskan LUX Multimode Microplate Reader (Thermo Fisher Scientific Inc., Waltham, MA, USA). The results were calculated based on a formula provided by the manufacturer and presented as $\mathrm{nmol} / \mu \mathrm{L}$. 


\subsection{Statistical Analyses}

All data were analysed using ANOVA for the main and interactive effects of temperature $(\mathrm{T})$ and dietary BET (D) with pen as a random effect for all data except growth performance where pen was the unit of observation using GenStat version 16th (VSNi Ltd., Hemel Hempstead, UK). For physiological parameters and muscle TBARS the main and interactive effects of time (TM) were also included as repeated measures effects in the residual maximum likelihood model. Due to heterogeneity of variances in MFI these data were $\log _{10}$ transformed before analyses. Where there was an indication of an interaction $(p<0.10)$ a post-hoc least significance difference test was applied using $p<0.05$ as the criteria to separate means Differences were considered a trend when $0.10>p>0.05$ and significant when $p<0.05$.

\section{Results}

\subsection{Growth Performance}

There was no effect of T or dietary D on either ADFI, ADG or FCR between days 0 and 21 of the experiment (Table 1). However, from day 21 to 35 ADG was reduced (90.2 vs. 80.2 g/day, $p=0.005$ ) with no change in ADFI or FCR in response to HS (Table 1). Dietary BET increased ADG (81.1 vs. $89.3 \mathrm{~g} /$ day, $p=0.023$ ) but did not effect ADFI or FCR between days 21 and 35. Over the entire experiment, there was a reduction in ADG (56.4 vs. $51.6 \mathrm{~g} /$ day, $p=0.009$ ) with no change in ADFI or FCR in response to HS (Table 1). Dietary BET tended to increase ADG (52.5 vs. $55.5 \mathrm{~g} /$ day, $p=0.094)$ between days 0 and 35 but had no significant effect on ADFI or FCR. As a result of the effects on ADG, final live weight was decreased by HS (2011 vs. $1845 \mathrm{~g}, p=0.009$ ) and tended to be increased by BET (1876 vs. $1980 \mathrm{~g}$, $p=0.092)$.

Table 1. Effect of betaine (BET) on average daily weight gain, average daily feed consumption and feed conversion ratio and final slaughter weight during thermoneutral (TN) and heat stress (HS) conditions.

\begin{tabular}{cccccccccc}
\hline Temperature (T) & \multicolumn{2}{c}{ TN } & \multicolumn{2}{c}{ HS } & \multicolumn{3}{c}{$p$-Value } \\
\hline Diet (D) & CON & BET & CON & BET & SED $^{\mathbf{1}}$ & T & D & T $\times$ D \\
\hline Average daily weight gain, g/day & & & & & & & & \\
0 to 21 days & 33.6 & 34.0 & 33.4 & 31.8 & 1.52 & 0.27 & 0.57 & 0.32 \\
21 to 35 days & 84.4 & 96.0 & 77.7 & 82.7 & 4.58 & 0.005 & 0.023 & 0.14 \\
0 to 35 days & 53.9 & 58.8 & 51.1 & 52.1 & 2.42 & 0.009 & 0.094 & 0.26 \\
0 to 21 days & & & & & & & & & 0.81 \\
21 to 35 days & 48.7 & 50.4 & 45.4 & 45.1 & 5.93 & 0.33 & 0.86 & 0.31 \\
0 to 35 days & 147 & 150 & 128 & 148 & 11.0 & 0.22 & 0.17 & 0.62 \\
Fverage feed consumption, g/day & 87.9 & 90.2 & 78.5 & 86.2 & 7.48 & 0.23 & 0.36 & \\
0 to 21 days & & & & & & & & \\
21 to 35 days & 1.46 & 1.48 & 1.45 & 1.43 & 0.162 & 0.78 & 0.98 & 0.85 \\
0 to 35 days & 1.76 & 1.58 & 1.60 & 1.80 & 0.159 & 0.78 & 0.96 & 0.12 \\
Slaughter weight, g & 1.65 & 1.53 & 1.54 & 1.66 & 0.131 & 0.93 & 0.95 & 0.23 \\
& 1925 & 2097 & 1827 & 1862 & 85.1 & 0.009 & 0.092 & 0.26 \\
\hline
\end{tabular}

\subsection{Physiological Responses}

Heat stress increased rectal temperature $(p<0.001)$ with the response being greatest $(p<0.001)$ during the afternoon when ambient temperature was highest (Figure 1a) and towards the end of the experiment (Figure 1b). Dietary BET decreased rectal temperature $(p<0.001)$ with the response being greatest in those chickens exposed to HS, during the afternoon when the temperature was highest (Figure 1a) and towards the end of the experiment (Figure 1b) as indicated by $\mathrm{TM} \times \mathrm{D}(p<0.001)$, $\mathrm{T} \times \mathrm{D}(p<0.001)$ and $\mathrm{T} \times \mathrm{TM} \times \mathrm{D}(p<0.001)$ interactions. Consequently, on the afternoon of day 34 of age $\mathrm{HS}$ increased rectal temperature by $1.1^{\circ} \mathrm{C}$ in the $\mathrm{CON}\left(41.6\right.$ vs. $\left.42.7^{\circ} \mathrm{C}\right)$, whereas the BET diet had 
a rectal temperature of only $41.0^{\circ} \mathrm{C}$ during HS (Table 2). Respiration rate on day 34 was increased by HS (64.0 vs. $160 \mathrm{bpm}, p<0.001$ ), and was decreased in BET (122 vs. $102 \mathrm{bpm}, p=0.004$ ) (Table 2). However, there was a $\mathrm{T} \times \mathrm{D}$ interaction $(p=0.017)$ such that the increase in respiration rate in response to HS was greater in the CON (66.0 vs. $177 \mathrm{bpm}$ ) than in the BET (62.0 vs. $142 \mathrm{bpm}$ ) (Table 3).
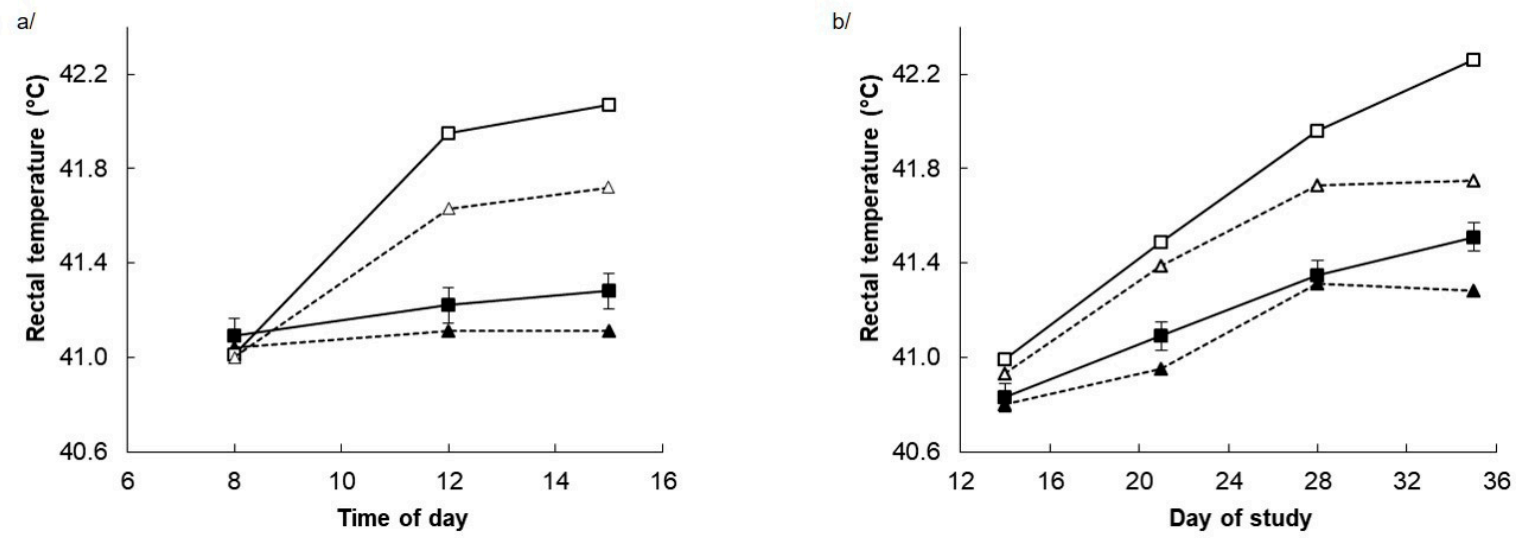

Figure 1. Rectal temperature in chickens fed either a control diet (CON, squares) or the CON diet plus betaine (BET, triangles) under either thermoneutral (filled symbols) or cyclic heat stress (open symbols). Panels (a) indicates the effect of time of day (TM) pooled across days of the experiment (DAY) with the standard error of the difference (SED) for the interaction between TM, environmental temperature (T) and diet (D) displayed on the data from the chickens receiving the CON diet. Panels (b) indicates the effect of DAY pooled across TM with the SED for the interaction between DAY, T and D displayed on the data from the chickens receiving the CON diet. There were main effects $(p<0.10)$ of $\mathrm{T}(p<0.001)$, DAY $(p<0.001)$, TM $(p<0.001)$ and D $(p<0.001)$ and interactive of T $\times$ DAY $(p<0.001), \mathrm{T} \times \mathrm{TM}$ $(p<0.001), \mathrm{DAY} \times \mathrm{TM}(p<0.001), \mathrm{TM} \times \mathrm{D}(p=0.005), \mathrm{DAY} \times \mathrm{D}(p<0.001), \mathrm{T} \times \mathrm{D}(p=0.053)$ and $\mathrm{T} \times \mathrm{DAY} \times \mathrm{TM}(p=0.042)$. There were no other main or interactive effects $(p<0.10)$.

\subsection{Blood and Plasma Parameters and Muscle Betaine}

Blood $\mathrm{pH}$ was increased by HS (7.34 vs. 7.40, $p=0.017)$ and tended to be increased by BET (7.36 vs. 7.40, $p=0.096)$ (Table 2). However, there was an interaction $(p=0.003)$ such that HS increased blood $\mathrm{pH}$ in the $\mathrm{CON}$ (7.27 vs. 7.45) whereas it was elevated under both thermal environments in those fed BET (7.41 vs. 7.38). Blood $\mathrm{pCO}_{2}$ was decreased by HS (51.6 vs. $43.1 \mathrm{~mm} \mathrm{Hg}$ ) whereas there was no main effect of BET. However, there was an interaction $(p=0.050)$ such that $\mathrm{HS}$ decreased blood $\mathrm{pCO}_{2}$ in the CON (55.6 vs. $40.1 \mathrm{~mm} \mathrm{Hg}$ ) whereas it was low under both thermal environments in those fed BET (47.6 vs. $46.1 \mathrm{~mm} \mathrm{Hg}$ ). There was no main effect of $\mathrm{HS}$ on blood total $\mathrm{CO}_{2}, \mathrm{pO}_{2}, \mathrm{O}_{2}$ saturation, $\mathrm{HCO}_{3}$, anion gap and base excess (Table 2). There were also no main effects of BET on blood total $\mathrm{CO}_{2}$, $\mathrm{pO}_{2}, \mathrm{O}_{2}$ saturation and $\mathrm{HCO}_{3}$ while dietary BET decreased the anion gap (17.9 vs. $16.5 \mathrm{mM}, p=0.050$ ) and tended to increase base excess (1.53 vs. $3.34 \mathrm{mM}, p=0.080)$. However, there were interactions such that the $\mathrm{CON}$ under TN conditions had lower total $\mathrm{CO}_{2}(p=0.054), \mathrm{HCO}_{3}(p=0.033)$, and base excess $(p=0.006)$ and higher anion gap $(p<0.001)$ than the other groups (Table 2$)$.

There was no effect of HS on blood haematocrit while it was decreased by the BET (19.3 vs. $18.0 \%$, $p=0.050$ ) (Table 3). Similarly, there was no effect of HS on blood haemoglobin concentrations whereas it tended to be decreased by dietary BET (6.53 vs. $6.14 \%, p=0.058$ ). However, there was an indication of an interaction $(p=0.093)$ such that haemoglobin concentrations were only decreased by dietary BET under TN conditions. Blood potassium ( 6.45 vs. $5.63 \mathrm{mM}, p=0.029)$ and sodium (150 vs. $148 \mathrm{mM}, p=0.056$ ) concentrations were decreased during HS but there was no effect on blood chloride or calcium concentrations (Table 3). While there was no main effect of BET on any of these blood mineral concentrations, there was an interaction such that blood potassium concentrations were decreased by HS in the CON (6.78 vs. $5.20 \mathrm{mM})$ but not the BET ( 6.13 vs. $6.07 \mathrm{mM})$. Blood lactate concentrations were decreased by HS (7.97 vs. $5.23 \mathrm{mM}, p=0.017)$ and tended to be decreased 
by BET (7.26 vs. $5.95 \mathrm{mM}, p=0.069)$. However, there was an interaction such that blood lactate concentrations were markedly decreased by HS the CON $(10.80$ vs. $3.76 \mathrm{mM})$ whereas this was not the case in the BET diet (5.19 vs. $6.70 \mathrm{mM}$ ). Blood glucose concentrations tended to be increased by HS (14.1 vs. $14.8 \mathrm{mM}, p=0.093$ ) whereas there was no effect of BET. Plasma $\mathrm{T}_{3}(4.69 \mathrm{vs.} 5.79 \mathrm{pg} / \mathrm{mL}$, $p=0.009)$ and $\mathrm{T}_{4}(6.62$ vs. $9.66 \mathrm{pg} / \mathrm{mL}, p=0.016)$ concentrations were increased by HS. Plasma $\mathrm{T}_{3}$ concentrations tended to be increased in BET (4.87 vs. $5.62 \mathrm{pg} / \mathrm{mL}, p=0.069)$ whereas plasma $\mathrm{T}_{4}$ concentrations remained unchanged.

Table 2. Effect of betaine (BET) on rectal temperature, respiration rate, acid/base balance and blood gas during thermoneutral (TN) and heat stress (HS) conditions.

\begin{tabular}{ccccccccc}
\hline Temperature (T) & \multicolumn{2}{c}{ TN } & \multicolumn{2}{c}{ HS } & \multicolumn{3}{c}{$p$-Value } \\
\hline Diet (D) & CON & BET & CON & BET & SED $^{\mathbf{1}}$ & T & D & T $\times$ D \\
\hline Rectal temperature, ${ }^{\circ} \mathrm{C}$ & 41.6 & 41.3 & 42.7 & 42.0 & 0.11 & $<0.001$ & $<0.001$ & 0.005 \\
Respiration, bpm & 66.0 & 62.0 & 177 & 142 & 8.30 & $<0.001$ & 0.004 & 0.017 \\
pH & 7.27 & 7.41 & 7.45 & 7.38 & 0.034 & 0.017 & 0.09 & 0.003 \\
$\mathrm{pCO}_{2}, \mathrm{~mm} \mathrm{Hg}_{\text {Total } \mathrm{CO}_{2}, \mathrm{mM}}$ & 55.6 & 47.6 & 40.1 & 46.1 & 4.47 & 0.023 & 0.53 & 0.050 \\
pO $_{2}, \mathrm{~mm} \mathrm{Hg}$ & 27.4 & 31.5 & 29.8 & 28.5 & 1.76 & 0.79 & 0.17 & 0.054 \\
$\mathrm{O}_{2}$ saturation, $\%_{\mathrm{HCO}}, \mathrm{mM}$ & 30.6 & 35.4 & 32.8 & 34.2 & 4.38 & 0.87 & 0.29 & 0.59 \\
Anion gap, $\mathrm{mM}$ & 48.6 & 66.6 & 64.8 & 63.7 & 9.11 & 0.32 & 0.15 & 0.17 \\
Base excess, $\mathrm{mM}$ & 25.7 & 30.1 & 28.5 & 27.1 & 1.68 & 0.95 & 0.13 & 0.033 \\
& 20.8 & 14.8 & 15.0 & 18.3 & 1.28 & 0.26 & 0.050 & $<0.001$ \\
& -1.18 & 4.95 & 4.23 & 1.73 & 1.78 & 0.40 & 0.080 & 0.006 \\
\hline
\end{tabular}

${ }^{1}$ Standard error of the difference for $\mathrm{T} \times \mathrm{D}$.

Table 3. Effect of betaine (BET) on haematology, electrolytes, metabolites, plasma thyroid hormones, betaine distribution and branched chain amino acid during thermoneutral (TN) and heat stress (HS) conditions.

\begin{tabular}{ccccccccc}
\hline Temperature (T) & \multicolumn{2}{c}{ TN } & \multicolumn{2}{c}{ HS } & \multicolumn{3}{c}{$p$-Value } \\
\hline Diet (D) & CON & BET & CON & BET & SED $^{\mathbf{1}}$ & T & D & T $\times$ D \\
\hline Haematocrit, $\%$ & 19.5 & 17.3 & 19.0 & 18.7 & 0.917 & 0.50 & 0.050 & 0.17 \\
Hgb $^{2}, \mathrm{~g} / \mathrm{dL}$ & 6.65 & 5.88 & 6.40 & 6.40 & 0.296 & 0.53 & 0.058 & 0.09 \\
Potassium, mM & 6.78 & 6.13 & 5.20 & 6.07 & 0.453 & 0.029 & 1.00 & 0.040 \\
Sodium, $\mathrm{mM}$ & 151 & 149 & 148 & 148 & 1.1 & 0.056 & 0.18 & 0.13 \\
Chloride, $\mathrm{mM}$ & 112 & 110 & 110 & 109 & 1.7 & 0.35 & 0.43 & 0.82 \\
Calcium, $\mathrm{mM}$ & 1.51 & 1.50 & 1.48 & 1.47 & 0.042 & 0.25 & 0.78 & 0.88 \\
Lactate, $\mathrm{mM}$ & 10.8 & 5.19 & 3.76 & 6.70 & 1.348 & 0.017 & 0.069 & 0.001 \\
Glucose, $\mathrm{mM}$ & 14.2 & 14.0 & 15.1 & 14.4 & 0.53 & 0.09 & 0.33 & 0.58 \\
$\mathrm{~T}_{3}, p \mathrm{~g} / \mathrm{mL}$ & 4.11 & 5.27 & 5.62 & 5.96 & 0.547 & 0.009 & 0.069 & 0.30 \\
$\mathrm{~T}_{4}, p \mathrm{pg} / \mathrm{mL}$ & 6.95 & 6.29 & 9.56 & 9.75 & 1.64 & 0.016 & 0.85 & 0.72 \\
Plasma betaine, $\mu \mathrm{mol} / \mathrm{L}$ & 133 & 164 & 102 & 140 & 10.9 & $<0.001$ & $<0.001$ & 0.66 \\
Muscle betaine, $\mu \mathrm{mol} / \mathrm{g}$ & 246 & 174 & 131 & 194 & 30.2 & 0.047 & 0.83 & 0.008 \\
BCAA, $\mathrm{nmol} / \mathrm{uL}$ & 3.25 & 2.09 & 1.98 & 1.82 & 0.204 & $<0.001$ & $<0.001$ & 0.002 \\
\hline
\end{tabular}

${ }^{1}$ Standard error of the difference for $\mathrm{T} \times \mathrm{D} .{ }^{2}$ Haemoglobin $(\mathrm{Hgb})$; Triiodothyronine $\left(\mathrm{T}_{3}\right)$; Thyroxine $\left(\mathrm{T}_{4}\right)$; Branched chain amino acid (BCAA).

Plasma betaine concentrations were decreased by HS (149 vs. $121 \mu \mathrm{mol} / \mathrm{L}, p<0.001)$ and were increased in the BET (118 vs. $152 \mu \mathrm{mol} / \mathrm{L}, p<0.001$ ). Muscle betaine concentrations were decreased by HS ( 210 vs. $163 \mu \mathrm{mol} / \mathrm{g}, p=0.047)$. While there was no main effect of BET on muscle betaine concentrations there was an interaction $(p=0.008)$ such that muscle betaine concentrations were highest in the CON under TN conditions and lowest in those consuming the CON diet under HS conditions ( $246 \mathrm{vs} .131 \mu \mathrm{mol} / \mathrm{g}$ ). The betaine concentration in muscle obtained from the BET were intermediate and not different (Table 3). 
Branch chain amino acid was decreased by HS $(2.67$ vs. $1.90 \mathrm{nmol} / \mu \mathrm{L}, p<0.001)$ and BET ( $2.62 \mathrm{vs.} 1.95 \mathrm{nmol} / \mu \mathrm{L}, p<0.001)$. There was an interaction $(p=0.002)$ such that BCAA was higher in the CON diet under TN conditions compared to other groups (Table 3 ).

\subsection{Objective Meat Quality}

The water content of breast muscle tended to be decreased after HS (77.70 vs. $76.10 \%, p=0.089)$ and was increased by BET (75.50 vs. $78.30 \%, p=0.008$ ) (Table 4). Drip loss of the breast muscle tended to be decreased by HS $(2.29$ vs. $1.82 \%, p=0.082)$ and was decreased by BET $(2.54$ vs. $1.57 \%, p=0.001)$. There was no effect of either HS or BET on cooking loss of the breast muscle. There was no effect of HS on shear force whereas shear force was decreased by BET ( 24.40 vs. $18.90 \mathrm{~N}, p<0.001)$. Carbonyl units were increased by HS ( $2.62 \mathrm{vs} .3 .33 \mathrm{nmol} / \mathrm{mg}, p=0.053)$ and decreased by BET ( $3.50 \mathrm{vs.} 2.46 \mathrm{nmol} / \mathrm{mg}$, $p=0.008)$. The myofibrillar fragmentation index tended to be decreased by HS ( $92.30 \mathrm{vs.} 68.61, p=0.081)$ and was increased by BET (63.61 vs. 97.30, $p=0.017$ ) (Table 4). There was little effect of either HS or BET on meat color with the exception that BET tended to increase $a^{*}(1.44$ vs. $1.93, p=0.10)$ (Table 5$)$. There were significant changes in meat color between $24 \mathrm{~h}$ and $72 \mathrm{~h}$ post-slaughter with a decrease in $L^{*}(56.22$ vs. $50.91, p<0.001)$, and a decrease in $a^{*}(1.97$ vs. $1.27, p=0.006)$ and $b^{*}(5.70$ vs. 4.75 , $p<0.001)$. There was no main effect of HS on the $\mathrm{pH}$ of breast muscle $(p=0.36)$ while $\mathrm{pH}$ decreased over time post-slaughter (6.80 vs. 6.53 and 5.86 at $10 \mathrm{~min}, 1 \mathrm{~h}$ and $24 \mathrm{~h}$ post-slaughter, $p<0.001$ ) and was increased by BET (6.33 vs. 6.47, $p=0.020$ ) (Table 5). However, there were interactions such that the effects of BET were most pronounced at $24 \mathrm{~h}$ post-slaughter, particularly under TN conditions.

Table 4. Effect of betaine (BET) on chicken breast (pectoralis major) objective eating quality measures after being housed under thermoneutral (TN) and heat stress (HS) conditions.

\begin{tabular}{ccccccccc}
\hline Temperature (T) & \multicolumn{2}{c}{ TN } & \multicolumn{2}{c}{ HS } & \multicolumn{3}{c}{$p$-Value } \\
\hline Diet (D) & CON & BET & CON & BET & SED $^{\mathbf{1}}$ & T & D & T $\times$ D \\
\hline Water content, \% & 76.2 & 79.1 & 74.7 & 77.5 & 1.42 & 0.089 & 0.008 & 0.96 \\
Drip loss, \% & 2.95 & 1.62 & 2.13 & 1.52 & 0.393 & 0.082 & 0.001 & 0.22 \\
Cooking loss, \% & 22.8 & 21.2 & 21.5 & 20.3 & 1.69 & 0.36 & 0.26 & 0.88 \\
Peak shear force, N & 24.1 & 18.6 & 24.8 & 19.1 & 1.87 & 0.49 & $<0.001$ & 0.92 \\
Carbonyl, nmol/mg protein & 3.22 & 2.02 & 3.77 & 2.89 & 0.486 & 0.053 & 0.008 & 0.64 \\
MFI $^{2}$ & 1.88 & 2.04 & 1.72 & 1.93 & 0.105 & 0.081 & 0.017 & 0.74 \\
& $(75.2)$ & $(109)$ & $(52.0)$ & $(85.1)$ & & & & \\
\hline
\end{tabular}

${ }^{1}$ Standard error of the difference for $\mathrm{T} \times \mathrm{D} .{ }^{2}$ Myofibrillar fragmentation index (MFI). Data were skewed so were $\log _{10}$-transformed before analysis. Back-transformed means are in parentheses.

Table 5. Effect of betaine (BET) and time post-slaughter on chicken breast (pectoralis major) colour and $\mathrm{pH}$ after being housed under thermoneutral (TN) and heat stress (HS) conditions.

\begin{tabular}{cccccccccc}
\hline \multicolumn{2}{c}{ Temperature (T) } & \multicolumn{2}{c}{ TN } & \multicolumn{2}{c}{ HS } & \multicolumn{3}{c}{$p$-Value } \\
\hline Diet (D) & Time (TM) & CON & BET & CON & BET & SED $^{\mathbf{1}}$ & T & D & TM \\
\hline $\mathrm{L}^{*}$ & $24 \mathrm{~h}$ & 55.5 & 58.6 & 55.7 & 55.2 & 2.22 & 0.48 & 0.20 & $<0.001$ \\
& $72 \mathrm{~h}$ & 50.1 & 52.5 & 50.6 & 51.0 & & & & \\
$\mathrm{a}^{*}$ & $24 \mathrm{~h}$ & 1.99 & 2.22 & 1.54 & 2.40 & 0.605 & 0.27 & 0.10 & 0.022 \\
& $72 \mathrm{~h}$ & 1.55 & 1.47 & 0.69 & 1.63 & & & & \\
$\mathrm{~b}^{*}$ & $24 \mathrm{~h}$ & 6.07 & 6.09 & 5.11 & 5.69 & 0.781 & 0.34 & 0.21 & 0.015 \\
& $72 \mathrm{~h}$ & 4.46 & 5.18 & 4.50 & 5.11 & & & & \\
$\mathrm{pH}^{2}$ & $10 \mathrm{~min}$ & 6.77 & 6.78 & 6.83 & 6.82 & 0.144 & 0.36 & 0.020 & $<0.001$ \\
& $1 \mathrm{~h}$ & 6.44 & 6.57 & 6.60 & 6.50 & & & & \\
& $24 \mathrm{~h}$ & 5.72 & 6.30 & 5.60 & 5.82 & & & & \\
\hline
\end{tabular}

${ }^{1}$ Standard error of the difference for $\mathrm{T} \times \mathrm{D} .{ }^{2} \mathrm{TM} \times \mathrm{T} p=0.023 ; \mathrm{TM} \times \mathrm{D} p=0.009 ; \mathrm{T} \times \mathrm{D} p=0.008$. 
Breast muscle TBARS increased between $24 \mathrm{~h}$ and $72 \mathrm{~h}$ post-slaughter $(1.64 \mathrm{vs} .3 .06 \mathrm{mg} / \mathrm{kg}, p<0.001)$, was increased by HS ( $2.12 \mathrm{vs.} 3.03 \mathrm{mg} / \mathrm{kg}, p=0.017)$ and was decreased by BET ( $3.06 \mathrm{vs} .2 .10 \mathrm{mg} / \mathrm{kg}$, $p=0.008)$ (Figure 2). There was an interaction between time post-slaughter and BET ( $p=0.036)$ such that BET decreased TBARS to a greater extent after $72 \mathrm{~h}(4.37 \mathrm{vs} .2 .66 \mathrm{mg} / \mathrm{kg})$ than at $24 \mathrm{~h}$ (1.74 vs. $1.54 \mathrm{mg} / \mathrm{kg}$ ) post-slaughter (Figure 2).

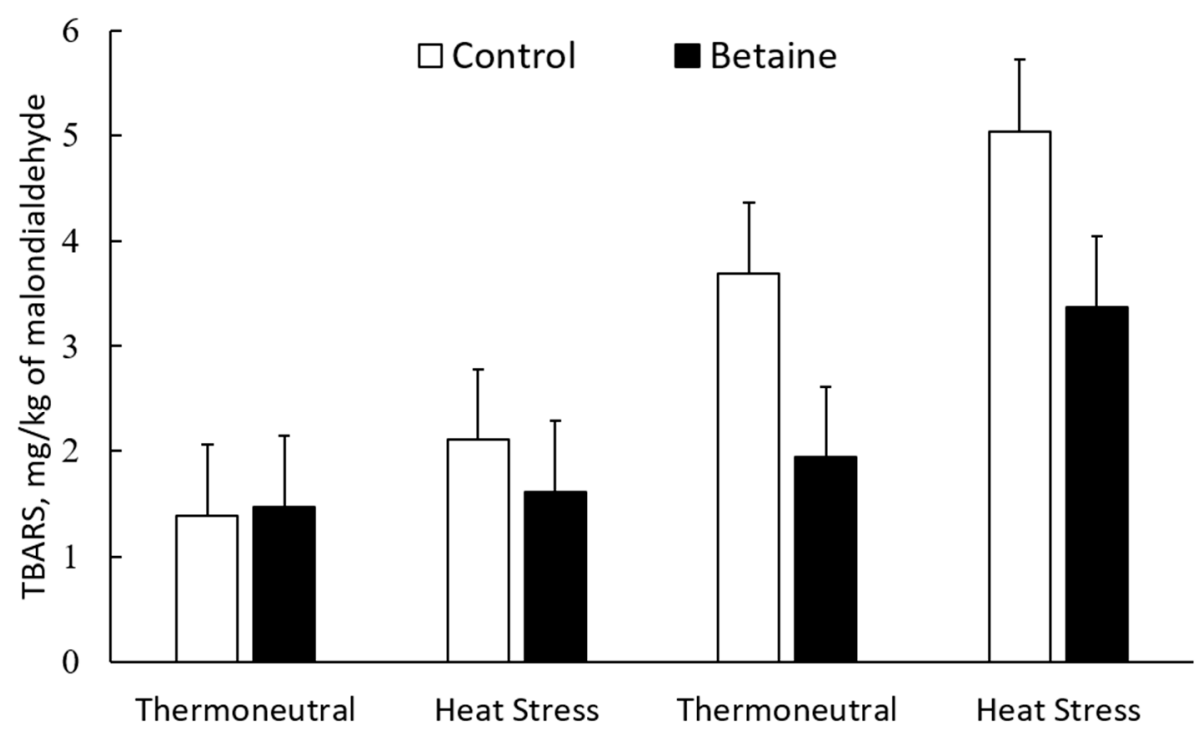

24 hours

72 hours

Figure 2. Effect of heat stress, dietary betaine, and time post-slaughter on breast muscle thiobarbituric acid reactive substances (TBARS) in $\mathrm{mg} / \mathrm{kg}$ of malondialdehyde. Data are mean and standard error of the difference for the interaction between environmental temperature (T), diet (D) and time post-slaughter (TM). There were main effects $(p<0.10)$ of T $(p=0.017)$, TM $(p<0.001)$ and $\mathrm{D}(p=0.008)$ and an interactive of TM $\times \mathrm{D}(p=0.036)$. There were no other main or interactive effects $(p<0.10)$.

\section{Discussion}

The major finding from this experiment was that dietary BET could reverse some of the negative effects of HS on growth performance, physiology, acid base balance and meat quality in contemporary broiler chickens. The effects of HS and dietary BET on ADG and final live weight confirm our previous findings $[11,14]$ and of others $[13,16]$. The effects were such that there was no significant difference between the final live weight of the CON diet under TN conditions and those consuming the BET diet during HS. The ability of dietary BET to reduce rectal temperature during peak HS towards the end of the experiment was quite profound, particularly given the rapid growth rate. The same was true for respiration rate. These data are again consistent with our previous observations $[11,14]$ and those of [17]. The protective effects of dietary BET are most likely multifaceted but at least part of the effect on rectal temperature and respiration rate is though to be due to it's osmo-protective effects. Betaine, or tri-methyl glycine, is a naturally occurring amino acid derivative found in many plant and invertebrate species. Physiologically, BET has a crucial osmoregulatory action and has been reported to improve growth performance by reducing the maintenance energy requirements by reducing the need for sodium/potassium pumping to maintain cellular osmolarity $[18,19]$. As a result, heat production is decreased with a resultant reduction in the amount of heat dissipated, rectal temperature and respiration rate. Furthermore, reduction of BCAA in the BET groups could lead to better growth performance as BCAA might use to synthesis protein and reduced protein breakdown [20,21], and stimulates glucose uptake in skeletal muscle that provides energy sources for tissues [22]. However, literature on this topic in broiler chickens are still limited and further studies are required to delineate the role of BCAA. 
There has been relatively little research conducted on the effects of HS on chicken meat quality. Genetic improvement has meant that modern poultry with their rapid lean growth are more susceptible to HS than non-selected or indigenous breeds because of their higher heat production. In this context, there is a negative relationship between rectal temperature, susceptibility to HS and production traits in chickens [23-25]. Thus, modern genotypes have lower survival rates, growth rate, body weights, and feed efficiency, and higher rectal temperature than slow-growing breeds when exposed to HS conditions [26,27]. Genetic selection for rapid muscle growth in poultry has altered the ability of animals to respond and adapt to environmental stressors such as HS. For example, in the present experiment there was an increase in plasma $T_{3}$ and $T_{4}$ in response to HS which is counter to the normally observed natural thermoregulatory reduction in plasma thyroid hormone concentrations observed in birds and mammals during exposure to elevated temperatures [28]. Although this is in contrast to our previous experiment [14], others have seen that modern avian genotypes exhibit increased plasma thyroid concentrations during HS. For example, several Japanese quail and chicken genotypes that have been selected for lean rapid growth display elevated plasma thyroid hormone concentrations during HS, which is not the case for non-selected lines [29]. Similarly, turkeys from non-selected lines produced stable thyroid responses to HS compared with commercial lines [30].

Increased thyroid response during HS could influence meat quality through increasing the incidence of pale soft and exudative (PSE) meat. Although, there was no change in plasma $\mathrm{Ca}^{2+}$ concentrations during HS in the current experiment, the Ca content in skeletal muscle is regulated by $\mathrm{T}_{3}$ and $\mathrm{T}_{4}$. Pale soft and exudative meat may occur as the result of muscle hyper-metabolism mediated by increased $\mathrm{Ca}^{2+}$ release from the sarcoplasmic reticulum or by direct action on the ryanodine receptor increasing the open state of the channel [30,31]. In this context, breast muscle from broiler chickens exposed to chronic HS exhibited increased muscle glycolysis as evidenced by increased muscle lactate and lower $\mathrm{pHu}$ resulting in paler meat with a greater cooking loss than meat from chickens reared under TN conditions [32]. Similarly, the breast muscle from turkeys exposed to HS had lower $\mathrm{pH}$ and was paler and had greater drip and cooking loss than muscles from chickens maintained under TN conditions [33]. It was found that cyclic HS resulted in paler meat and lower ultimate $\mathrm{pH}$ than that observed in chickens housed under TN conditions [34]. Despite the increase in plasma $\mathrm{T}_{3}$ and $\mathrm{T}_{4}$, there was no evidence of PSE during HS in the present experiment since there was no change in meat color and $\mathrm{pH}$ while drip loss and muscle water content were actually lower during HS. However, there was an increase in MFI indicating an increase in post-mortem myofibrillar breakdown in response to HS. Previously we have observed an increase in MFI and a decrease in cooking loss and muscle water content but no change in drip loss after HS [14]. Others have also observed a reduction in cooking loss during HS although in that experiment the meat was paler and had a high $\mathrm{pHu}$ after the chickens were exposed to HS [35]. Therefore, it appears that there is no consistent effect of HS on the incidence of PSE meat in chickens with perhaps the potential negative effects being offset by reduced water content due to dehydration of the meat. Interestingly, dietary BET reversed the effects of HS on muscle MFI and water content while reducing drip loss indicating improvements in eating quality under both $\mathrm{TN}$ and HS conditions. Also, of interest, BET resulted in elevated $24 \mathrm{~h} \mathrm{pH}$, particularly in the TN chickens, which would explain the higher total water content of BET muscles. As high ultimate $\mathrm{pH}$ is well-known to be associated with higher water-holding capacity due to reduced charge between myofilaments [36].

There was no effect of HS on WBSF which is consistent with our previous findings [14]. In contrast, others have found that HS increased WBSF in chickens compared to their counterparts held under TN conditions [32]. Interestingly, dietary BET reduced WBSF regardless of thermal environment. Cyclic HS resulted in oxidation of chicken meat as evidenced by the increase in TBARS and carbonyl concentrations, with the increase in TBARS being more pronounced with time post-slaughter. These findings indicate that HS is a major cause of oxidative stress in chickens as it is in other species [37,38]. Increased lipid and protein oxidation characterized by increased TBARS and microbiological growth, color deterioration, and shorter shelf life of the breast have been reported in broiler chickens housed 
under HS conditions [39-41]. Importantly, dietary BET was able to counteract the effects of HS on oxidation and even reduce oxidation under TN conditions.

\section{Conclusions}

This experiment clearly demonstrated that HS decreased growth and increased respiration rate and rectal temperature in broilers with resultant deleterious effects on meat quality. Supplemental BET was able to ameliorate the effects of HS on growth and physiological parameters. Importantly, dietary BET was able to reduce oxidation, myofibrillar protein fragmentation and WBSF under both TN and HS conditions.

Author Contributions: Conceptualization, M.S., J.J.C., and F.R.D.; Data curation, M.S., and F.R.D.; Formal analysis, J.J.C., and F.R.D.; Funding acquisition, S.W., J.J.C., F.R.D.; and R.D.W.; Investigation, J.J.C., M.S., and H.H.L.; Methodology, M.S., H.H.L., J.J.C., R.D.W., H.A.R.S. and F.R.D.; Project administration, J.J.C., F.R.D., and M.S.; Resources, J.J.C., S.W.; and F.R.D.; Supervision, F.R.D., J.J.C., and S.W.; Writing-original draft, M.S., and F.R.D.; Writing-review and editing, M.S., J.J.C., and F.R.D. All authors have read and agreed to the published version of the manuscript.

Funding: This experiment was supported by The University of Melbourne, Melbourne International Research Scholarship and Melbourne International Fee Remission Scholarship.

Acknowledgments: We are thankful to all staff of the research facility for their assist throughout the experiment. We would also like to thank Tri Foods Pty. Ltd. for providing and transporting the chickens' feed.

Conflicts of Interest: There is no conflict of interest regarding the publication of the article. S.W. is employed by Feedworks Australia who provided the betaine and manufactured the diets used in these experiments.

\section{References}

1. Henry, B.; Charmley, E.d.; Eckard, R.; Gaughan, J.B.; Hegarty, R. Livestock production in a changing climate: Adaptation and mitigation research in Australia. Crop Pasture Sci. 2012, 63, 191-202. [CrossRef]

2. Temim, S.; Chagneau, A.M.; Peresson, R.; Tesseraud, S. Chronic heat exposure alters protein turnover of three different skeletal muscles in finishing broiler chickens fed 20 or $25 \%$ protein diets. J. Nutr. 2000, 130, 813-819. [CrossRef]

3. Akşit, M.; Yalcin, S.; Özkan, S.; Metin, K.; Özdemir, D. Effects of temperature during rearing and crating on stress parameters and meat quality of broilers. Poult. Sci. 2006, 85, 1867-1874. [CrossRef]

4. Love, J.D.; Pearson, A.M. Lipid oxidation in meat and meat products-A review. J. Am. Oil Chem. Soc. 1971, 48, 547-549. [CrossRef]

5. Huang, C.; Jiao, H.; Song, Z.; Zhao, J.; Wang, X.; Lin, H. Heat stress impairs mitochondria functions and induces oxidative injury in broiler chickens. J. Anim. Sci. 2015, 93, 2144-2153. [CrossRef] [PubMed]

6. Shakeri, M.; Cottrell, J.J.; Wilkinson, S.; Zhao, W.; Le, H.H.; McQuade, R.; Furness, J.B.; Dunshea, F.R. Dietary Betaine Improves Intestinal Barrier Function and Ameliorates the Impact of Heat Stress in Multiple Vital Organs as Measured by Evans Blue Dye in Broiler Chickens. Animals 2020, 10, 38. [CrossRef]

7. DiGiacomo, K.; Leury, B.J.; Dunshea, F.R. Potential nutritional strategies for the amelioration or prevention of high rigor temperature in cattle-a review. Anim. Prod. Sci. 2014, 54, 430-443. [CrossRef]

8. Cottrell, J.J.; Ponnampalam, E.N.; Dunshea, F.R.; Warner, R.D. Effects of infusing nitric oxide donors and inhibitors on plasma metabolites, muscle lactate production and meat quality in lambs fed a high quality roughage-based diet. Meat Sci. 2015, 105, 8-15. [CrossRef]

9. Craig, S.A.S. Betaine in human nutrition. Am. J. Clin. Nutr. 2004, 80, 539-549. [CrossRef]

10. Alirezaei, M.; Gheisari, H.R.; Ranjbar, V.R.; Hajibemani, A. Betaine: A promising antioxidant agent for enhancement of broiler meat quality. Br. Poult. Sci. 2012, 53, 699-707. [CrossRef]

11. Shakeri, M.; Cottrell, J.J.; Wilkinson, S.; Ringuet, M.; Furness, J.B.; Dunshea, F.R. Betaine and Antioxidants Improve Growth Performance, Breast Muscle Development and Ameliorate Thermoregulatory Responses to Cyclic Heat Exposure in Broiler Chickens. Animals 2018, 8, 162. [CrossRef] [PubMed]

12. Alirezaei, M.; Khoshdel, Z.; Dezfoulian, O.; Rashidipour, M.; Taghadosi, V. Beneficial antioxidant properties of betaine against oxidative stress mediated by levodopa/benserazide in the brain of rats. J. Physiol. Sci. 2015, 65, 243-252. [CrossRef] [PubMed] 
13. He, S.; Zhao, S.; Dai, S.; Liu, D.; Bokhari, S.G. Effects of dietary betaine on growth performance, fat deposition and serum lipids in broilers subjected to chronic heat stress. Anim. Sci. J. 2015, 86, 897-903. [CrossRef] [PubMed]

14. Shakeri, M.; Cottrell, J.J.; Wilkinson, S.; Le, H.H.; Suleria, H.A.R.; Warner, R.D.; Dunshea, F.R. Growth Performance and Characterization of Meat Quality of Broiler Chickens Supplemented with Betaine and Antioxidants under Cyclic Heat Stress. Antioxidants 2019, 8, 336. [CrossRef]

15. Fagan, J.M.; Sleczka, B.G.; Sohar, I. Quantitation of oxidative damage to tissue proteins. Int. J. Biochem. Cell Biol. 1999, 31, 751-757. [CrossRef]

16. Nofal, M.E.; Magda, A.G.; Mousa, S.M.M.; Doaa, M.M.Y.; Bealsh, A.M.A. Effect of dietary betaine supplementation on productive, physiological and immunological performance and carcass characteristic of growing developed chicks uinder the condition of heat stress. Egypt Poult. Sci. 2015, 35, 237-259.

17. Attia, Y.; Hassan, R.; Qota, E. Recovery from adverse effects of heat stress on slow-growing chicks in the tropics 1: Effect of ascorbic acid and different levels of betaine. Trop. Anim. Health Prod. 2009, 41, 807-818. [CrossRef]

18. Schrama, J.; Heetkamp, M.; Simmins, P.; Gerrits, W. Dietary betaine supplementation affects energy metabolism of pigs. J. Anim. Sci. 2003, 81, 1202-1209. [CrossRef]

19. Suster, D.; Leury, B.J.; King, R.H.; Mottram, M.; Dunshea, F.R. Interrelationships between porcine somatotropin (pST), betaine, and energy level on body composition and tissue distribution of finisher boars. Aust. J. Agric. Res. 2004, 55, 983-990. [CrossRef]

20. Wolfe, R.R. Branched-chain amino acids and muscle protein synthesis in humans: Myth or reality? J. Int. Soc. Sports Nutr. 2017, 14, 30. [CrossRef]

21. Chen, X.; Zhang, Q.; Applegate, T. Impact of dietary branched chain amino acids concentration on broiler chicks during aflatoxicosis. Poult. Sci. 2016, 95, 1281-1289. [CrossRef] [PubMed]

22. Nie, C.; He, T.; Zhang, W.; Zhang, G.; Ma, X. Branched chain amino acids: Beyond nutrition metabolism. Int. J. Mol. Sci. 2018, 19, 954. [CrossRef]

23. Cooper, M.; Washburn, K. The relationships of body temperature to weight gain, feed consumption, and feed utilization in broilers under heat stress. Poult. Sci. 1998, 77, 237-242. [CrossRef] [PubMed]

24. Settar, P.; Yalcin, S.; Turkmut, L.; Ozkan, S.; Cahanar, A. Season by genotype interaction related to broiler growth rate and heat tolerance. Poult. Sci. 1999, 78, 1353-1358. [CrossRef] [PubMed]

25. Lu, Q.; Wen, J.; Zhang, H. Effect of chronic heat exposure on fat deposition and meat quality in two genetic types of chicken. Poult. Sci. 2007, 86, 1059-1064. [CrossRef]

26. Yalcin, S.; Özkan, S.; Türkmut, L.; Siegel, P. Responses to heat stress in commercial and local broiler stocks. 1. Performance traits. Br. Poult. Sci. 2001, 42, 149-152. [CrossRef] [PubMed]

27. Deeb, N.; Shlosberg, A.; Cahaner, A. Genotype-by-environment interaction with broiler genotypes differing in growth rate. 4. Association between responses to heat stress and to cold-induced ascites. Poult. Sci. 2002, 81, 1454-1462. [CrossRef]

28. Collin, A.; Cassy, S.; Buyse, J.; Decuypere, E.; Damon, M. Potential involvement of mammalian and avian uncoupling proteins in the thermogenic effect of thyroid hormones. Domest. Anim. Endocrinol. 2005, 29, 78-87. [CrossRef]

29. Bowen, S.; Washburn, K. Thyroid and adrenal response to heat stress in chickens and quail differing in heat tolerance. Poult. Sci. 1985, 64, 149-154. [CrossRef]

30. Chiang, W.; Booren, A.; Strasburg, G. The effect of heat stress on thyroid hormone response and meat quality in turkeys of two genetic lines. Meat Sci. 2008, 80, 615-622. [CrossRef]

31. Strasburg, G.; Chiang, W. Pale, soft, exudative turkey-The role of ryanodine receptor variation in meat quality. Poult. Sci. 2009, 88, 1497-1505. [CrossRef] [PubMed]

32. Zhang, Z.; Jia, G.; Zuo, J.; Zhang, Y.; Lei, J.; Ren, L.; Feng, D. Effects of constant and cyclic heat stress on muscle metabolism and meat quality of broiler breast fillet and thigh meat. Poult. Sci. 2012, 91, 2931-2937. [CrossRef] [PubMed]

33. Sams, A. The effect of seasonal heat stress on rigor development and the incidence of pale, exudative turkey meat. Poult. Sci. 1997, 76, 1616-1620. 
34. Akter, Y.; Libinaki, R.; Hutchison, C.; Hopcroft, R.; Edwards, A.C.; Edwards, M.; O'Shea, C.J. Optimisation and investigations into the effect of a phosphorylated tocopherol mixture on growth performance, meat quality and plasma inflammatory biomarkers in broilers. Anim. Feed Sci. Technol. 2019, 253, 181-190. [CrossRef]

35. Dai, S.; Gao, F.; Xu, X.; Zhang, W.; Song, S.; Zhou, G. Effects of dietary glutamine and gamma-aminobutyric acid on meat colour, $\mathrm{pH}$, composition, and water-holding characteristic in broilers under cyclic heat stress. Br. Poult. Sci. 2012, 53, 471-481. [CrossRef]

36. Hamm, R. Functional properties of the myofibrillar system and their measurements. In Muscle as Food, 1st ed.; Bechtel, P.J., Ed.; Academic Press: UniCambridge, MA, USA, 1986; pp. 135-199.

37. Chauhan, S.; Celi, P.; Leury, B.; Clarke, I.; Dunshea, F. Dietary antioxidants at supranutritional doses improve oxidative status and reduce the negative effects of heat stress in sheep. J. Anim. Sci. 2014, 92, 3364-3374. [CrossRef]

38. Liu, F.; Cottrell, J.J.; Furness, J.B.; Rivera, L.R.; Kelly, F.W.; Wijesiriwardana, U.; Pustovit, R.V.; Fothergill, L.J.; Bravo, D.M.; Celi, P.; et al. Selenium and vitamin E together improve intestinal epithelial barrier function and alleviate oxidative stress in heat-stressed pigs. Exp. Physiol. 2016, 101, 801-810. [CrossRef]

39. Wang, R.; Pan, X.; Peng, Z. Effects of heat exposure on muscle oxidation and protein functionalities of pectoralis majors in broilers. Poult. Sci. 2009, 88, 1078-1084. [CrossRef]

40. Mujahid, A.; Pumford, N.R.; Bottje, W.; Nakagawa, K.; Miyazawa, T.; Akiba, Y.; Toyomizu, M. Mitochondrial oxidative damage in chicken skeletal muscle induced by acute heat stress. J. Poult. Sci. 2007, 44, 439-445. [CrossRef]

41. Imik, H.; Atasever, M.A.; Urcar, S.; Ozlu, H.; Gumus, R.; Atasever, M. Meat quality of heat stress exposed broilers and effect of protein and vitamin E. Br. Poult. Sci. 2012, 53, 689-698. [CrossRef]

(C) 2020 by the authors. Licensee MDPI, Basel, Switzerland. This article is an open access article distributed under the terms and conditions of the Creative Commons Attribution (CC BY) license (http://creativecommons.org/licenses/by/4.0/). 